\title{
O lugar da performance na música indeterminada cageana
}

\author{
Valério Fiel da Costa (Universidade Federal da Paraíba, João Pessoa, PB, Brasil)
}

fieldacosta@gmail.com

\begin{abstract}
Resumo: Reflexão sobre o status do performer no âmbito da indeterminação musical cageana, com a prerrogativa de definir a forma musical de tal modo que o próprio compositor seria capaz de surpreender-se com o resultado. Pretende-se demonstrar que tal corolário funciona, na prática, a despeito do enunciado principal, como uma ferramenta refinada de controle do intérprete. Tal conclusão nos leva à necessidade de pensar uma musicologia capaz de não apenas incluir a performance como instância criativa do processo musical, mas de propô-la como item prioritário de uma mudança paradigmática da área.

Palavras-chave: John Cage; Indeterminação em música; Criatividade em performance.
\end{abstract}

The place of performance in John Cage’s indeterminate music

Abstract: Reflection on the status of the performer in the context of the cageanmusical indeterminacy inwhich this would have the prerogative to define the musical form in such a way the composer himself would be able to be surprised with the result. It is intended to demonstrate that such a corollary works, in practice, in spite of the main statement, as a refined tool of controlof the performer. This conclusion leads us to the need of thinking a musicology capable to, not only including performance as creative instance of the musical process, but proposing it as a priority item for a paradigmatic change of the area.

Keywords: John Cage; Indeterminacy in music; Creativity in performance.

\section{Introdução}

O termo indeterminação, em música, à maneira como foi enunciado por John Cage (1912-1992) em diversos textos, conferências e entrevistas, pode ser assim sintetizado: a possibilidade de que uma obra musical soe de maneiras diversas, sujeita ao arbítrio do intérprete, possibilitando ao compositor uma atitude de ouvinte inadvertido (CAGE, 1973, tradução nossa) ${ }^{1}$, só pode ser considerada pertinente num ambiente conceitual no qual o texto musical (partitura) remeta-se de forma imediata aum resultado sonoro que lhe seja correlato, segundo um critério de solfejo.

De fato, se a conexão entre texto e resultado sonoro aqui não fosse fundamental, não poderia ser considerada relevante a ideia de desobrigação entre ambos. Se o texto musical contém a obra ou a possibilidade da obra, funcionando como um "duplo", a indeterminação cageana marca, sem dúvida, uma ruptura radical com as ideias de autoria, obra, projeto composicional etc.; tal é, de fato, o status conceitual da empreitada que nos é revelada no momento em que abordamos a obra do compositor, buscando reconhecer nela as bases de uma originalidade radical pautada na desconstrução da lógica sobre a qual toda a tradição moderna da música ocidental se erige; a saber, o paradigma da autonomia do texto musical.

Os processos de individualização do ato composicional, da alienação entre compositor e intérprete, da autonomia do texto musical - que passa a valer como "obra" a partir do século XVIII (GOEHR, 1992, p. 206) - a divisão de trabalho que se consolida com a constituição dos conservatórios e ampliação das orquestras sinfônicasno decorrer do século XIX, entre outros fatores, são elementos fundamentais para se compreender o status da obra musical e de sua morfologia no momento em que isto foi novamente posto em questão, em meados do século XX, pela prática da música experimental norte-americana.

A autonomização da obra musical pela via da sua transformação num bem de consumo, passível de reprodução e distribuição em grande escala, se dá concomitantemente ao estabelecimento da coincidência definitiva entre a obra musical e um texto que lhe seria 
correlato; relação que definiria o solfejo como padrão seguro de definição morfológica para uma classe consumidora específica, relativamente abastada, e cada vez mais abrangente. A partir do século XVIII, a obra musical pôde, sem prejuízo alguma uma práxis performática, transitar em formato de partitura. A premissa dessa autonomia é que o autor poderia fixar-lhe, de direito, uma representação fiel da ideia composicional que, por sua vez, seria programada para ressurgir diante do fruidor, graças à execução disciplinada de intérpretes. A morfologia da obra musical ${ }^{2}$, segundo essa tradição, seria um dado a priori, anterior ao texto, e a função do intérprete seria a de garantir, da forma mais íntegra possível, que essa morfologia ressurgisse na situação de concerto e diante de um público atento. O intérprete serviria como uma espécie de "máquina" que, quando bem programada, cumpriria da melhor forma possível tal demanda. Sua participação no processo, porém, acabaria funcionando como um obstáculo, uma espécie de "mal necessário", uma vez que seriajustamente no ato da execução que "algo poderia dar errado"; poderia não se cumprir o objetivo que animou todo o processo, em outras palavras, que a obra musical não se manifestasse tal qual foi concebida e/ou idealizada. O ônus do fracasso de tal cadeia produtiva recairia sempre nele, sendo a parte frágil e humana do processo de materialização da ideia musical3. Nesse paradigma, o responsável pela produção da morfologia que seria própria da determinada obra, aquilo que conteria sua "identidade”, como algo discernível de outras obras ou de um entorno imediato, seria o compositor.

A proposição cageana de uma música na qual o autor como que se retiraria, totalmente ou em parte, do seu processo de definição morfológica em proveito de intérpretes criadores foi recebida como uma atitude radical e mesmo paradigmática de uma nova maneira de se conceber música. Aqui, o intérprete é elevado ao status de agente não somente ativo, mas prioritário, na concepção da obra.

\section{Alguns conceitos cageanos}

Uma das facetas da proposta de redefinição paradigmática de Cage é o uso do acaso como metodologia de estruturação musical a partir de fins dos anos 40. Como forma de desambiguação: o uso do acaso em Cage consistia na presença de algum tipo de sorteio durante o processo composicional e visava à definição e à fixação de itens partiturais; a indeterminação implicaria a cessão de liberdades ao intérprete no ato de execução da obra. Vamos primeiramente examinar o segundo caso, buscando conectá-lo ao primeiro em momento oportuno, para verificarmos de que modo (se) o paradigma clássico, de autonomia do texto, foi posto em questão dentro de tal proposta. Insisto: a ideia de indeterminação em música, tomada à maneira como foi enunciada, pressupõe uma ruptura com o modelo tradicional no que diz respeito à supressão da prerrogativa autoral na definição da morfologia da obra e no papel da partitura como guia estrito que levaria diretamente a determinada sonoridade. Em outras palavras, Cage teria destruído o idealismo da obra enquanto a priori do processo musical, transferido o ato criativo para o intérprete e colocado o compositor em pé de igualdade com o ouvinte como sujeito de um fruir inadvertido. Tal fórmula servirá como espécie de batismo para uma práxis de música experimental que vigora até hoje e que motivou diversos debates a respeito dos limites daquilo que poderia (ou deveria) ser considerado música ${ }^{4}$.

Cage não estava, porém, exclusivamente preocupado em fazer funcionar uma máquina conceitual pautada na liberdade autoral do intérprete. Ao passo em que via como indispensável uma práxis performática capaz de funcionar sem o recurso a estratégias coercitivas ou apelos à autoridade do compositor, suas críticas ao mau uso da liberdade cedida a determinados intérpretes eram frequentes. É relativamente fácil encontrar, em entrevistas 
e conferências suas, desabafos cujo mote é a indisciplina do performer; sobre apresentações de seu Concert for Piano and Orchestra (1958), por exemplo, peça basilar do indeterminismo cageano: "Eu preciso encontrar um jeito de dar liberdade às pessoas sem que elas se tornem idiotas, de modo que esta liberdade as enobreça. Como farei isso?” (CAGE, 1969, p. 136). Tal declaração poderia ser entendida como fato contextual, uma vez que o desentendimento entre compositor e intérprete num ambiente de mudança paradigmática (o da música indeterminada) seria previsível. No entanto, o desentendimento entre Cage e os intérpretes parece permear toda a sua carreira. Em meados da década de 40, por exemplo, ao ouvir a preparação realizada por um pianista de sua peça Perilous Night (1944), fora enfático: "Sua preparação de piano era tão pobre que eu desejei na época nunca ter escrito a música" (BUNGER, 1981, p. 6). É possível, outrossim, admitir que todo o desenvolvimento do piano preparado durante os anos 40 se deveu à dificuldade do compositor em lidar com músicos percussionistas que, "por estarem ocupados demais ganhando dinheiro" (FLEMMING; DUCKWORTH, 1989, p. 20), não compareciam aos ensaios. Esse fato levou Cage a adotar uma espécie de estratégia de sobrevivência pautada na praticidade do piano preparado - que visava emular o piano de cauda transformando-o numa espécie de "ensemble de percussão dos pobres" (PRITCHETT, 1996, p. 24) a ser tocado pelo próprio compositor durante sessões de acompanhamento de dança.

Essa queixa à indisciplina do intérprete se tornou recorrente e foi defendida durante toda a sua carreira como uma espécie de problema padrão no que diz respeito à execução de sua música. Nesse contexto, a "descoberta” do pianista David Tudor em 1950 representou um marco no encaminhamento da questão uma vez que o compositor agora podia ilustrar, através da impecável atitude performática do colega, qual seria a melhor maneira de se executar suas obras. A enigmática proposição de que bastaria ao intérprete abdicar de seus gostos e desgostos pessoais - "A liberdade que proponho não é dada para permitir qualquer coisa que se queira fazer, trata-se de um convite para que as pessoas se libertem de seus gostos e desgostos pessoais e se disciplinem" (KOSTELANETZ, 2003, p. 108) - para fazer um bom trabalho, parecia aderir naturalmente ao ascetismo disciplinar de Tudor:

Dar liberdade ao intérprete individual me interessa cada vez mais. [...] Dada a indivíduos como David Tudor, claro, gera resultados que são extraordinariamente belos. Quando essa liberdade é dada a indivíduos sem disciplina e que não partem - como digo em vários textos - do zero [...], que não são, em outras palavras, indivíduos mudados, mas que permanecem como indivíduos com seus gostos e desgostos, daí, claro, dar liberdade não interessa (KOSTELANETZ, 2003, p. 72).

Por outro lado, há também em Cage certo empenho em delimitar alguns resultados sonoros como correlatos a tal atividade performática disciplinada. As principais chaves estariam 1) no contato de Cage com a musicista indiana Gita Sarabhai. Ela revelou ao compositor, através da leitura de Ramakrishna, que a função da arte indiana seria a de "aquietar a mente para torná-la suscetível a influência divina” (PRITCHETT, 1996, p. 37), que levou Cage a produzir uma sequência relativamente extensa de peças singelas de caráter intimista a partir de meados dos anos 405, nas quais o compositor pretendia desobrigar a composição musical da necessidade de expressar sentimentos; e, a mais importante, 2) numa alegoria descoberta, em fins dos anos 40, no livro The Transformation of Nature in Art, do pensador indiano Ananda Coomaraswami, segundo a qual, a arte deveria "imitar a natureza em seu modo de operação” (PRITCHETT, 1996, p. 37). Aqui não seria o caso de tentar produzir algo idêntico à Natureza, à maneira como esta se apresenta aos sentidos, mas procurar se valer do modo como ela geraria sua complexidade para produzir um ambiente sonoro sempre ori- 
ginal e surpreendente, no qual os sons seriam "eles mesmos": "Deve-se desistir do desejo de controlar o som e pôr-se a descobrir maneiras de deixar os sons serem eles mesmos mais do que veículos de teorias feitas pelo homem ou expressão de sentimentos humanos" (CAGE, 1973, p. 10). Ou que, em outras palavras, soassem como se não tivessem sido determinados por uma vontade autoral. Estamos diante do germe conceitual do acaso cageano6, como já se pode intuir, mas também diante de um filtro estetizante capaz de orientar determinadas ações performáticas em determinado sentido.

Aceita-se que a obra cageana, a partir de fins dos anos 50, prescinde da noção de autor e de projeto estético, por conta de orientações de primeira mão do tipo:

Quando está claro que a pessoa que está montando a peça está realizando seu trabalho não apenas no espírito da composição, mas de modo a se libertar de suas escolhas, daí acho que não há diferença no que diz respeito ao resultado, porque não estamos na verdade interessados em resultados. Resultados são como mortes. O que nos interessa são coisas acontecendo e mudando, não nelas se fixando. (para Cole Gagne \& Tracy Caras - 1975). (KOSTELANETZ, 2003, p. 108)

Se não há nenhuma expectativa a respeito de resultados sonoros, então não há o que discutir a respeito de morfologia em Cage. Essa seria inatingível, uma vez que suas peças sempre portariam formatos diferentes. A grande quantidade de queixas do compositor a respeito das performances de suas obras, por outro lado, deixa claro que havia um projeto estético por trás de sua poética.

\section{0 "Monstro de Frankenstein" cageano}

Enquanto a ideia de indeterminação pressupunha uma espécie de ênfase no performer (e na liberdade criativa deste), que se tornara relevante como elemento de definição morfológica, a ideia de acaso operava em sentido oposto, ao enfatizar a partitura e sua feitura. Além disso, o acaso à maneira como foi usado por Cage, tendia a potencializar dificuldades técnicas de execução. Ao decidir a disposição de itens do texto a partir de operações de acaso, era comum que surgissem situações não-idiomáticas e/ou tecnicamente inexecutáveis. Sabemos que obras complexas como Music of Changes (1952), por exemplo, requereram intervenção in loco de David Tudor como consultor e que este corrigiu muitas páginas da partitura para viabilizá-la para fins performáticos (CHARLES, 2005, p. 4). O resultado final, como esperado, representa um desafio enorme ao intérprete não tanto pela sua complexidade rítmico-melódica, mas pelo seu nãoidiomatismo radical. Isso decorre da eliminação de pontos de apoio narrativo, tais como cadências e, de modo geral, de uma relação causal e/ou afirmativa entre sinais de articulação e fraseado. $\mathrm{O}$ acaso operaria aqui contra tal narratividade ao gerar situações, não apenas contraditórias, mas até mesmo paradoxais. Ocorre que tal partitura está definida em seus mínimos detalhes sem margem para redefinição morfológica patente: cada item foi gerado através de tabelas de material, dinâmica e durações; assim, o objeto musical em questão se configura como um "pacote", fruto de cruzamento paramétrico e sua especificidade é tão absoluta quanto um "ponto" dentro de uma estrutura serial pontilista de um compositor como Pierre Boulez. Longe de se configurar como uma saída humanizante, o uso do acaso aqui acentua a ideia de compromisso com o texto ao qual o intérprete se vê sujeito pela tradição musical vigente: imerso num ambiente sonoro completamente novo, sem referências a clichês de fraseologia, só resta a ele obedecer de forma plena à partitura. O próprio Cage propõe uma imagem emblemática de tal princípio quando compara Music of Changes a um monstro de Frankenstein: 
A Music of Changes é um objeto mais inumano que humano uma vez que operações de acaso a trouxeram à tona. O fato dessas coisas que a constituem, embora sejam apenas sons, tenham sido agrupadas para controlar um ser humano, o performer, dá à obra o aspecto alarmante de um Monstro de Frankenstein. (CAGE, 1973, p. 36)

O acaso na obra cageana poderia ser visto como uma etapa preliminar à aventura do indeterminismo de fins da década de 50 se considerarmos apenas o aspecto técnico-metodológico de definição de morfologias. O compositor proporia como que dois passos num processo de eliminação da ideia de autoria: um primeiro no qual se desistiria de organizar a forma dentro da estrutura de forma racional ${ }^{7}$ (porém, em sério prejuízo da liberdade do intérprete) e um segundo no qual se abriria mão definitivamente de qualquer tutela estético-ideológica do ato performático. Esse viés provê que o indeterminismo em Cage seria correlato a um ideal de liberdade criativa e demandaria, portanto, uma nova problematização do ato performático, vinculado até então a um funcionalismo de execução do texto musical.

Observo, porém, que se parte aqui não de um projeto de emancipação do intérprete, mas, pelo contrário, de uma estratégia de controle que vai sendo refinada com o passar do tempo graças a um acúmulo de casos emblemáticos.

\section{Acaso e controle}

Elenco aqui algumas estratégias amplamente utilizadas pelo compositor no intuito de regrar resultados sonoros e/ou comportamentos dentro de um ambiente de indeterminismo musical e o papel que cabe ao intérprete em tais casos.

Uma das estratégias retóricas mais usadas por Cage para ilustrar o modo correto de executar suas peças é a referência a condutas interpretativas exemplares de músicos acostumados a tocar com ele. David Tudor foi, sem dúvida, como vimos antes, o seu principal exemplo. Não apenas porque era capaz de executar partituras no limite do humanamente possível, mas porque ostentava uma atitude disciplinada que lhe permitia abordar peças de caráter indeterminado cumprindo de forma plena a ideia de deixar os sons serem eles mesmos. Para Cage, a fórmula para se alcançar tal desempenho envolveria a capacidade de "libertar a mente de seus gostos e desgostos pessoais", e Tudor (assim como Cunningham, Duchamp, ele próprio etc.) forneceu bons exemplos desse tipo de conduta. Não é necessário revisar a longa lista de declarações de Cage a respeito da conduta do intérprete para entendermos que tais indivíduos só podiam ser usados como exemplares, porque praticavam a música em questão em convívio direto com o compositor, foram mobilizados por ele de acordo com características de conduta que lhe interessavam e que, enfim, faziam parte de um coletivo marcado por certa diretriz estético-ideológica.

Nem sempre foi possível a Cage contar com intérpretes familiares no decorrer de sua carreira, porém. Não havia, por exemplo, como garantir resultados sonoros ou uma disciplina equivalente junto a grupos orquestrais. De fato, as duas peças mais citadas por Cage quando este denuncia a indisciplina do intérprete como fator de barbárie, são o Concert for Piano and Orchestra (1958) e Atlas Eclipticalis (1961). O relativo fracasso na execução de tais trabalhos ilustra bem a carência de estratégias à disposição do compositor para resolver problemas relativos à emancipação do intérprete ${ }^{8}$.

A chave para uma boa interpretação de obras de Cage residiria mais na imitação de comportamentos randômicos, do que numa disciplina de desligamento da mente ${ }^{9}$. Grupos de renome como Les Percussions de Strasbourg, por exemplo, quando executam peças do compositor nas quais é exigida improvisação, não hesitam em aplicar, como clichê obriga- 
tório, o acaso ou a "impressão de acaso" como estratégia performática, como descreve muito bem Tom Johnson em seu estudo sobre intencionalidade em Cage:

Cada músico [do Les Percussions de Strasbourg] deve interpretar sua parte como se ele estivesse sozinho, sem ser influenciado pelo que os outros intérpretes estão fazendo. A ideia é deixar sua parte tocar por ela mesma, não ser afetada pelo que os outros músicos fazem, e, acima de tudo, nunca coordenar-se propositadamente com os outros músicos. (JONHSON, 1989, p. 267).

Nesse caso, a demanda é cumprida sem que seja necessário acessar estados mentais de caráter paradoxal, como sugerido pelo compositor. No entanto, estamos ainda fora de uma situação de liberdade interpretativa, uma vez que os resultados são medidos em função da expectativa do compositor.

Durante os anos 60, Cage investiu em peças de caráter aberto, nas quais o próprio intérprete era convidado a produzir a partitura ${ }^{10}$. Via de regra, tal procedimento era realizado através de uma operação como, por exemplo, a sobreposição ao acaso de folhas transparentes (contento pontos ou linhas) sobre uma superfície qualquer ${ }^{11}$. Tal resultado era anotado e passava a servir como guia para uma performance. O detalhe é que Cage sugeria que, além da operação de acaso inicial (que já serviria para alcançar um resultado de feição randômica), o intérprete deveria vincular o resultado de tais operações a itens mais ou menos "fixos", tais como clusters, sons de rádio, notas longas ou curtas, ações variadas etc. No fim das contas, o que estava em jogo era a simples disposição ao acaso de itens cuja continuidade (ou mútua causalidade) era comprometida pela sua singularidade: objetos fechados em si e dispostos no tempo numa sequência aparentemente arbitrária. Isso gera, invariavelmente, resultados sonoros afins com um projeto estético manifesto na obra de Cage desde os anos 40 e que se caracteriza não apenas pela disposição de itens numa continuidade acausal, mas também pela singeleza e economia de materiais. Em outras palavras, trata-se de uma "máquina cageana”, espécie de algoritmo capaz de produzir resultados sonoros sempre satisfatórios segundo um projeto composicional que, mesmo dissimulado pela sua retórica, se apresenta como dado invariável na performance de suas obras. ${ }^{12}$

Nesse caso, a ideia de que seria do intérprete a prerrogativa de elaborar a peça não procede, pois ele está implicado no processo como mais um operador que, no caso, acumularia as tarefas de "gerador de randomismo" e de executante. É forçoso reconhecer, pelo contrário, que é sequestrada mais uma dimensão do processo criativo do intérprete e que a impressão de que algo foi elaborado por ele se deve mais ao fato de que a partitura foi produzida por um ato seu do que por suas ideias musicais interferirem no resultado sonoro. Entretanto, o mero ato de confeccionar o texto musical, segundo a lógica vigente, mesmo que por parte do músico executante não haja gerência alguma sobre o resultado sonoro, acaba sendo entendido como ato autoral. Tal juízo só pode ser entendido à luz dos critérios de uma tradição musical que coloca como "compositor" aquele que produz o "texto" e como "obra" aquilo que o texto conteria como mensagem a ser decifrada em performance.

Em Radio Music (1956) para de um a oito rádios, cada intérprete deve acionar uma sequência determinada de frequências em dials de rádio dentro de um lapso temporal determinado. A partitura propõe quatro seções, algumas das quais contendo uma quantidade tão grande de eventos que, mesmo buscando uma melhor economia do tempo dentro do teto estipulado, tais eventos deveriam forçosamente ser ativados numa frequência de aproximadamente um por segundo. Considerando que as frequências foram sorteadas previamente e anotadas com rigor na partitura, e que é virtualmente impossível acompanhá-las numa situação de performance tal qual estão definidas, só resta ao performer recorrer a uma ati- 
tude, também de efeito randomista, de busca por resultados. Aqui as frequências servem para guiar o gesto das mãos de alguém empenhado em seguir, de forma disciplinada, a norma partitural. O desejo do intérprete de obedecer a um imperativo de leitura partitural é, portanto, um item relevante e garante que ele não se aproprie do fluxo impondo a este suas idiossincrasias. O dado morfológico de saída é garantido independentemente de decisões interpretativas (e graças a isso).

Em Atlas Eclipticalis (1961), o acaso é também mobilizado como fator de controle do intérprete, mas, desta vez, funcionando como uma espécie de filtro. Aqui, os instrumentos da orquestra devem ser amplificados e os seus respectivos microfones ativados ou desativados segundo critérios randômicos ou improvisatórios do compositor durante o ato performático. Suas partes podem ou não soar como escritas - pois o esquema também prevê processamento ao vivo - ou mesmo ser canceladas durante o ato performático com o desligamento do microfone. O roteiro de performance da mesa de controle envolvia tanto operações de acaso, com o uso de tool pieces como Cartridge Music para determinar ações, quanto improvisação livre manipulando os sinais que emergiam eventualmente da orquestra (PIEKUT, 2011, p. 47). ${ }^{13}$

Outra ilustração do uso do acaso como forma de controle do intérprete num ambiente de aparente liberdade criativa é a gravação de estreia da peça Thirteen (para 13 intérpretes - 1992), encomendada pelo Ensemble Thirteen, grupo regido por Manfred Reichert. A peça, como todas as outras number pieces, se caracteriza por uma estratégia notacional que consiste na proposição de "janelas de tempo" (ou "parênteses de tempo" para usar o termo cageano) dentro das quais se deve executar sons específicos segundo critérios de "entrada" e "saída", em si flexíveis ${ }^{14}$. No caso do Ensemble Thirteen, foram realizadas operações de acaso para fixar o timming das notas de cada um dos intérpretes do grupo determinando um score que pudesse ser regido: "tenho consciência de que aqui não estou levando as coisas inteiramente ao acaso, mas John Cage há de me perdoar” (REICHERT, 1992, p.1). O efeito randomista já estaria garantido pelo algoritmo original, e os intérpretes poderiam executar a peça sem regência, inclusive, mas o diretor do grupo optou por realizar ele mesmo a fixação via operação de acaso; que soa verossímil, porque representa um recorte válido num universo de objetos capazes de satisfazer à demanda. Em outras palavras: uma vez dominado o algoritmo, qualquer um poderia fixar a peça em partitura e proceder segundo um modelo tradicional de execução de peças orquestrais.

Em 0’00”(4’33” n'2) de 1961, que propõe uma instrução direta no lugar de uma partitura, pede-se que o intérprete desempenhe uma ação disciplinada qualquer em amplificação máxima (sem microfonia). O texto foi produzido durante a performance de estreia e passou a evoluir desde então, com o acréscimo de algumas instruções complementares. Uma delas era que a ação disciplinada deveria servir a outros e que o intérprete não deveria performar a peça. Observamos que cabe ao intérprete apenas uma escolha: a da ação a desempenhar. Uma vez definida, segue-se que esta deve ser disciplinada, ou seja, não deve se desviar do objetivo previamente definido e deve ser executada da forma mais íntegra possível; deve servir como favorecimento a outros, ou seja, deve apresentar como resultado um produto de fato, capaz de servir a um uso definido (mesmo que seja a produção de algo imaterial ou poético) e tudo isso deve ser realizado sem que transpareça o ato performático, ou seja, que o performer seja capaz de dissimular ao máximo sua participação ativa (e criativa) no processo. O recurso à amplificação máxima sem microfonia ${ }^{15}$ visa, como já enunciamos num outro trabalho, a dois efeitos complementares que produzem um impacto morfológico importante: o aumento de relevância de sonoridades débeis e distorção de sonoridades robustas (COSTA; BRITO, 2015). A cena que nos é proposta resume-se a uma espécie de rea- 
dy-made extraído do cotidiano no qual o intérprete figura como um mero ativador de dados algorítmicos predeterminados, independentemente de sua escolha inicial, e o efeito global, de distorção sonora dos sons típicos daquela cena, produz um efeito de desterritorialização de impacto morfológico evidente e recorrente.

Finalmente, no Musicircus (1964), em que diversas fontes sonoras autônomas tocam juntas seus próprios repertórios, sem combinação prévia, ao vivo e no mesmo espaço, produzindo um efeito geral de caos determinístico, temos uma situação na qual cada músico, de fato, executa aquilo que lhe convém. Porém, é no efeito geral que o musicircus se realiza e não no detalhe. Em outras palavras, o músico é tragado pela textura geral e atua nesta como mais um componente. A informação gerada pelo seu set funciona como parte de uma trama maior, fora de seu controle, que deve ser fruída por ouvintes que percorrem o recinto, experimentando o efeito de tal imersão, focando sua escuta ora numa, ora noutra direção e reproduzindo a imagem de um sujeito autônomo mergulhado no rumor de uma multidão sem face ${ }^{16}$. Não discutiremos aqui questões éticas ou ideológicas que orientariam tal formato, mas nos interessa relevar que a produção de sua morfologia, apesar da autonomia legada ao intérprete, não só lhe foge ao controle, mas o aliena do resultado de sua própria ação. A ele é exigida a disciplina de executar rigorosamente o seu respectivo repertório evitando, deixar-se levar pelos demais grupos, tendo em vista que tal iniciativa não só denotaria uma ruptura com o princípio da interpenetração entre fontes diversas, mas tenderia a produzir um efeito pouco compatível com aquilo que se espera do musicircus como sonoridade; tal efeito indesejável foi evitado, segundo testemunho de Charles Junkerman, na ocasião da derradeira performance do Musicircus em 1992 em Stanford, através do uso de regentes (utilities), que percorriam a massa de intérpretes orientando-a, em tempo real, para garantir sua disciplina e, por consequência, uma morfologia geral considerada representativa do processo (JUNKERMAN, 1994, p.40).

\section{Considerações finais}

Podemos agora retornar ao paradigma morfológico pré-cageano (conservatorial) e ponderar a respeito do lugar da indeterminação e do papel do intérprete na sua poética. Iniciamos nossa reflexão afirmando que: 1) o indeterminismo em música exige como pressuposto que haja no critério de solfejo uma garantia de obra e 2) que, em não havendo, caberia ao intérprete criar, no lugar do compositor, uma obra "provisória”, que estaria sempre em aberto. Assim, a proposta cageana abrigaria uma mudança radical nos papéis estabelecidos pela tradição conservatorial entre criação e execução, uma vez que eliminaria num só golpe, digamos assim, o pressuposto da obra e da autoria. Da obra como coisa mais ou menos estável, previsível, especulável, preexistente e da autoria enquanto prerrogativa de um sujeito que busca uma determinada morfologia e que a logra obter através do recurso ao intérprete disciplinado.

O critério de solfejo, numa perspectiva do texto musical como nexo morfológico, encenaria a conexão entre enunciado e resultado, mas se revelaria inútil para propostas de caráter grafista ou instruções diretas: catástrofe da obra; o intérprete operaria num ambiente de múltiplas escolhas, e a morfologia que ora produziria soaria surpreendente para o próprio ativador do processo, o compositor: catástrofe da autoria.

Observamos que tal fórmula só poderia subsistir se desconsiderássemos o papel do processo de conformação morfológica de uma peça, prerrogativa do intérprete, no que concerne à definição de sua identidade formal. Ora, seria suficiente, no paradigma cageano, que a desconexão entre enunciado e resultado "do ponto de vista de um autor", fosse uma 
realidade e não que tal desconexão se desse em qualquer nível e em relação a qualquer observador.

Aqui a prerrogativa de definição morfológica é ainda vinculada ao compositor, nem que seja para declarar a ausência ou a presença de obra. Curiosamente, cogitar que uma determinada morfologia poderia ser considerada determinável por um agente "intermediário", tal como o intérprete, o que tornaria supérflua a ascendência de um autor prévio ao contexto, não tem servido como mote para analisar a questão. No entanto, é forçoso reconhecer que o ato performático acaba plasmando morfologias que, em relação à etapa anterior de proposição formal, são mais específicas, e que, entre indivíduos implicados nesse processo, ou seja, que contribuíram para tal engendramento in loco, não se experimenta do mesmo modo a sensação de indeterminismo suposta na proposição autoral. Isso significa que só há indeterminação, nos termos do enunciado cageano, num ambiente conceitual no qual o compositor determina o que seja "sua" obra. A pertença da obra orienta, mesmo que sua morfologia seja um dado a plasmar, seu status existencial, mesmo que isso implique numa contradição de fato.

No contexto de tal prática, acompanhando a lógica da relação entre compositor e intérprete legada pela tradição de divisão do trabalho, típica do ambiente conservatorial, a promessa velada de que o ato performático estaria em vias de uma problematização mais profunda, em virtude da assunção de que o intérprete tornara-se "como que um autor", não se realizou de fato. Ao invés disso, e por causa da ausência de tal problematização, acumulou-se na tradição cageana, uma lista de procedimento emblemáticos de um proceder capaz de levar a bom termo, e sob controle, seus produtos poéticos mesmo num ambiente de aparente negociação com o intérprete.

A chave para entender a poética cageana estaria no design algorítmico de suas propostas, mais do que na suposição de que seriam meros estímulos para a ação criativa (porém disciplinada) do intérprete. Opera-se sempre dentro de um rol de regras bem estabelecidas muitas vezes capazes de produzir resultados morfológicos específicos. Tais resultados demandariam do intérprete certa disciplina tanto no que concerne à obediência a tais regras, quanto ao recurso a modelos de conduta sugeridos pelo autor em suas declarações a respeito do tema. Ao invés de um novo paradigma capaz de vincular definitivamente uma dimensão criativa ao ato performático, temos uma estratégia de controle do intérprete e do resultado sonoro, muito mais refinada, pois dissimulada por uma retórica que atribui a este parte da prerrogativa de definição da obra. Na realidade, o performer atua mais como um operador, no sentido computacional do termo, agindo segundo um algoritmo cujo funcionamento se esforça por garantir. Nisso consistiria a "disciplina" do performer cageano exigida como condição para que, em suas músicas, os sons sejam eles mesmos. Em outras palavras, para que não reste nenhum sinal de autoria por parte do intérprete no resultado sonoro final, território que se mantém aqui como propriedade exclusiva do compositor.

Assim, há que se retomar a reflexão a respeito do papel do intérprete na música de caráter indeterminado e suas derivações, tanto americanas quanto europeias, reintroduzindo no jogo a performance como agente de produção morfológica por excelência e admitindo que é no ato performático que se dá, de fato, a criação musical nesse contexto ${ }^{17}$.

Uma teorização musical a partir da performance poderia ser estruturada a partir da premissa do músico que faz música à sua maneira a partir de determinado estímulo. Esse estímulo poderia ser de qualquer natureza: partitural, grafista, instrucional, inspiracional, improvisatória, mimética, algorítmica etc.

Finalmente, seria possível recolher de cada experiência musical específica o seu respectivo resultado sonoro e se poderia estudar o impacto morfológico de cada "dispara- 
dor” no contexto. O critério geral seria morfológico e não mais ontológico (CARON, 2011) e a obra poderia ocupar seu lugar conceitual justo como efeito de uma práxis performativa, admitindo o seu antigo (e típico) viés, causal, como coisa específica e necessariamente vinculada a uma determinada tradição. Pensamos que essa mudança de foco poderia contribuir para a estruturação de uma ciência musical performática mais robusta, autônoma, e afim com uma perspectiva de revalorização do músico performer enquanto propositor na área.

\section{Notas}

1 Texto original em inglês

2 Entende-se o termo morfologia aqui como o acontecimento sonoro propriamente dito, sua manifestação concreta, o modo como este se manifesta, independentemente de um ideal formal preestabelecido.

3 Para entender o contexto de autonomização do texto musical na segunda metade do século XVIII e no decorrer do século XIX, ver ATTALI, 2009; GOHER: 2013, que propõe, inclusive, que o termo "obra" teria uma espécie de "data de nascença", em torno de 1800, coincidente com o momento no qual a produção musical passa a ser vista "como o uso de material musical resultando em unidades de pertença pessoal completas, discretas, originais e fixas" (p. 206); ou ROSEN, 1988; que releva o impacto de uma demanda burguesa por música para consumo doméstico como alavancadora de um mercado próspero para o compositor enquanto criador, à revelia de uma práxis anterior pautada principalmente na divulgação de peças pela via performática direta. Nicholas Cook denuncia o apego da musicologia tradicional pela dicotomia entre processo e produto, sendo este último (a obra enquanto ideal) o foco da reflexão acadêmica da área. (COOK, 2006, p. 6)

4 Ver o importante artigo Alea (BOULEZ, 1964), no qual o compositor francês se empenha em denunciar o uso "negligente" do acaso, tece recomendações sobre como lidar com a liberdade do intérprete, de modo que essa se torne vantajosa ao projeto composicional, e propõe o termo aleatório como espécie de substituto ao indeterminado cageano; em seu livro sobre música experimental Michael Nyman delimita um 'campo da música experimental' usando a perspectiva cageana como mote e opõe, de forma categórica, uma práxis experimentalista norte americana a uma práxis vanguardista européia (NYMAN, 1981)

5 Tais como A Flower (1950), Wonderful Widow of Eighteen Springs (1942), Music for Marcel Duchamp (1947), String Quartet in Four Parts (1950), Sonatas \& Interludes (1949), Concerto for Prepared Piano and Chamber Orchestra (1951), entre outras.

${ }^{6}$ Há diversos outros fatores que levam Cage ao uso do acaso como metodologia de estruturação musical e que já foram exaustivamente tratados em outra ocasião (COSTA, 2016, capítulo 1). Aqui nosso interesse maior é chamar atenção para o conteúdo estetizante do uso do acaso como gerador de situações sonoras de perfil randomista.

7 Na verdade, Cage, ao usar o acaso como metodologia para criar a forma, se pauta por uma serie de critérios composicionais e, graças a isso, cada uma de suas peças "de acaso" possui um resultado morfológico próprio. Pritchett empenhou-se em demonstrar isso em The Music of John Cage (1999).

${ }^{8}$ Para maiores detalhes sobre as tentativas frustradas de execução de Atlas Eclipticalis, ver: PIEKUT, Benjamin. Experimentalism Otherwise: The New York Avant-Garde and Its Limits. Berkeley: University of California Press, 2011.

9 Mesmo porque aqui não se trata de "deixar o inconsciente falar sem filtros" uma vez que determinados clichês musicais (com sua indesejável referencialidade) poderiam emergir justamente devido a tal abordagem.

${ }^{10}$ Repertório que James Pritchett batizou de Tool Pieces. (PRITCHETT, 1996).

${ }^{11}$ Como ocorre em Music Walk (1958), Cartridge Music (1960) e Variations III (1963).

${ }^{12}$ Chamei tal procedimento de "síntese poética", pois resume num enunciado ou método, o funcionamento de uma máquina capaz de produzir obras do autor "x". O mesmo valeria para obras "em aberto" de compositores brasileiros como L. C. Vinholes ou Gilberto Mendes. Para mais detalhes, ver (COSTA, 2016, capítulo V) e (COSTA, MEDEIROS, 2014).

${ }^{13}$ Este viés, somado a uma série de outros fatores, tais como a presença constante de microfonias fora de controle durante os ensaios e mesmo no concerto, a uma resistência de Cage a tratar questões técnicas e a cuidar do convencimento dos músicos a respeito daquilo que deveria ocorrer, motivou um dos episódios mais paradigmáticos de "sabotagem" em performance da carreira do compositor quando, em 1964, vários músicos da Filarmônica de Nova York resolveram esmagar os microfones durante o concerto. Tal processo é detalhado em Piekut (2011, capítulo 1) - When Orchestra Attacks.

${ }^{14}$ Por exemplo, na peça Four^ 6 para quarteto de formação livre, no primeiro "parêntese" do primeiro instrumento da peça temos que o intérprete deve iniciar a execução de seu primeiro somentre 0'00" e 1'15" e concluí-la entre 0'55" e 2'05". Tal critério faz com que a sequência de eventos da peça, apesar de sempre mantida, engendre sobreposições sempre diversas. Numa proposta como essa, no caso de uma peça orquestral, o regente seria prescindível por razões óbvias. 
${ }^{15}$ Ou seja, o mais alto possível antes que ocorra o processo de retroalimentação entre microfones e alto falantes que destruiria a singularidade da sonoridade da ação.

${ }^{16}$ Charles Junkerman apresentou um excelente artigo sobre o musicircus cageano na coletânea John Cage: composed in America, de 1994, onde descreve e realiza profunda reflexão crítica da última performance desse tipo realizada pelo próprio Cage em Stanford em 1992.

17 É obvio que a performance como ato criativo é própria do fazer musical de modo geral. Entretanto, no âmbito das escolas indeterministas formais, soa dramática a relação entre criação e execução justamente porque estas emergiram de um contexto anterior no qual cabia ao intérprete apenas reproduzir itens predefinidos. O quanto essa relação de alienação entre agente e resultado é específica do "Ocidente" (portanto verdadeiramente sui generis) e correlata ao funcionamento do sistema capitalista, seria mote para outro trabalho.

\section{Referências}

ATTALI, Jacques. Noise: the political economy of music. Minneapolis/London: University of Minnesota Press, 2009. 190 p.

BOURDIEU, Pierre. As Regras da Arte: gênese e estrutura do campo literário. São Paulo: Companhia das Letras, 1996. $431 \mathrm{p}$.

BOULEZ, Pierre. Alea. Perspectives of New Music, Seattle,v.3, n.1, p.42-53, 1964.

BUNGER, Richard. The Wellprepared piano. San Pedro: Litoral Arts Press, 1981. 44 p.

CAGE, John. A Year from monday: new lectures and writings by John Cage. Middletown: Wesleyan, 1969. $179 \mathrm{p}$.

Silence: Lectures and writingsby John Cage. Middletown: Wesleyan, 1973. 312 p.

CARON, Jean-Pierre. Da Ontologia à Morfologia: reflexões sobre a identidade da obra musical. 2011. 150 f. Dissertação (Mestrado) - Instituto de Filosofia e Ciências Sociais da Universidade Federal do Rio de Janeiro, 2011.

CHARLES, Daniel. John Cage: Luring Music awayfromthe West? The Complete John Cage Edition, v.29. CD. Mode Records, 2005.

COOK, Nicholas. Entre o Processo e o produto: Música e/enquanto performance. Per Musi, Belo Horizonte, n.14, p.5-22, 2006.

COSTA, Valério Fiel da. Morfologia da Obra Aberta: esboço de uma teoria geral da forma musical. Curitiba: Prismas, 2016. 230 p.

. BRITO Luã Nóbrega.Padrões Morfológicos em duas peças de caráter aberto da Escola de Nova York. In: CONGRESSO DA ASSOCIAÇÃO NACIONAL DE PESQUISA E PÓS-GRADUAÇÃO EM MÚSICA, 25, 2015, Vitória. Anais... Campinas: ANPPOM, 2015.

- MEDEIROS, Danielly Mayara Dantas de. A Teoria Tempo-Espaço como ferramenta analítica para obras de caráter aberto de L. C. Vinholes: o caso da Instrução 61. In: Congresso da Associação Nacional de Pesquisa e Pós-Graduação em Música, 24, 2014, São Paulo. Anais... Campinas: ANPPOM, 2014.

FLEMING, Richard; DUCKWORTH, William (Ed.). John Cage at Seventy-Five. Lewinsburg: Bucknell University Press, 1989. 305 p.

GOEHR, Lidia. The Imaginary Museum of Musical Works: an essay in the philosophy of music. Oxford: Clarendon, 1992. 314 p.

JOHNSON, Tom. Intentionality and Non intentionality in the Performance of Music by John 
Cage. In: FLEMING, Richard; DUCKWORTH, William. John Cage at Seventy-Five. Lewinsburg: Bucknell University Press, 1989. p.262-269.

JUNKERMAN, Charles. nEw/ foRms of living together: The Model of the Musicircus. In: PERLOFF, Marjorie; JUNKERMAN, Charles (Org.). John Cage: Composed in America. Chicago: University of Chicago Press, 1994.p. 39-64.

KOSTELANETZ, Richard. Conversing with Cage. New York: Routledge, 2003. 352p.

NYMAN, Michael. Experimental Music: Cage and Beyond. New York: Schirmer, 1981. 218p.

PIEKUT, Benjamin. Experimentalism Otherwise: The New York Avant-Garde and Its Limits. Berkeley: University of California Press, 2011. 297 p.

PRITCHETT, James. The Music of John Cage. Cambridge: Cambridge University Press, 1996. $237 \mathrm{p}$.

REICHERT, Manfred. Thirteen. Mode Records, 1992.

ROSEN, Charles. Sonata Forms. New York: Norton, 1988. 432 p.

Valério Fiel da Costa - Compositor, pesquisador e performer paraense. Professor de composição e disciplinas teóricas no Departamento de Música da Universidade Federal da Paraíba (UFPB). Líder do grupo interdisciplinar de pesquisa Estudos em (Des)territorialização da Performance idealizador, junto a Fabio Cavalcante, da iniciativa de criatividade sonora Artesanato Furioso (2000) e seu atual coordenador. Bacharel em Composição, mestre e doutor em Processos Criativos pela Universidade de Campinas, tendo se dedicado ao estudo do piano preparado de John Cage, da indeterminação e do acaso aplicados à música. Um dos idealizadores do Encontro Nacional de Criatividade Sonora - ENCUN (2003), sendo que coordenou o evento em três ocasiões. Recentemente lançou pela Editora Prismas o livro Morfologia da obra aberta: esboço de uma teoria da forma musical (2016). É o atual coordenador do Programa de Pós-Graduação em Música da UFPB. 